\title{
Molecular Origin of the Sign Preference of Ion- Induced \\ Heterogeneous Nucleation in a Complex Ionic \\ pÿLiquid Diethylene Glycol System
}

\section{Keshavarz, Fatemeh}

2020-11-23

Keshavarz , F , Kubecka , J , Attoui , M , Vehkamäki , H , Kurten , T \& Kangasluoma , J 2020

, ' Molecular Origin of the Sign Preference of Ion- Induced Heterogeneous Nucleation in a pÿComplex Ionic Liquid Diethylene Glycol System ' , Journal of Physical Chemistry C , vol. pÿ124, no. 49 , pp. 2694426952 . https://doi.org/10.1021/acs.jpcc.0c09481

http://hdl.handle.net/10138/336601

https://doi.org/10.1021/acs.jpcc.0c09481

acceptedVersion

Downloaded from Helda, University of Helsinki institutional repository.

This is an electronic reprint of the original article.

This reprint may differ from the original in pagination and typographic detail.

Please cite the original version. 


\section{Molecular Origin of the Sign Preference of Ion- Induced Heterogeneous Nucleation in a Complex Ionic Liquid-Diethylene Glycol System}

Fatemeh Keshavarz $^{1 *}$, Jakub Kubečka ${ }^{1}$, Michel Attoui ${ }^{2}$, Hanna Vehkamäki ${ }^{1}$, Theo Kurtén ${ }^{3}$, Juha

$$
\text { Kangasluoma }^{1,4^{*}}
$$

${ }^{1}$ Institute for Atmospheric and Earth System Research / Physics, Faculty of Science, University of Helsinki, P.O. Box 64, 00014 Helsinki, Finland

${ }^{2}$ LISA, UMR7583, Université Paris-Est-Créteil, Université de Paris, Institut Pierre Simon Laplace (IPSL), Créteil, France

${ }^{3}$ Department of Chemistry, Faculty of Science, University of Helsinki, FI-00014, Finland

${ }^{4}$ Aerosol and Haze Laboratory, Beijing Advanced Innovation Center for Soft Matter Science and Engineering, Beijing University of Chemical Technology, 100029 Beijing, China

* Corresponding authors:

(Equal contributions)

Juha Kangasluoma: juha.kangasluoma@helsinki.fi

Fatemeh Keshavarz: fatemeh.keshavarz@helsinki.fi 
ABSTRACT: Heterogeneous nucleation on charged seeds has been shown to frequently prefer a given sign of electrical charge (anion or cation), at constant seed size and (apparent) chemical composition. For some systems, this sign preference can be readily understood in terms of individual chemical interactions. However, experiments are in general unable to provide satisfying molecularlevel explanations for the sign preference of chemically complex systems. Here, we experimentally demonstrate a positive sign preference for charged ionic liquid seeds (CILS) with diethylene glycol vapor (DEG), and explain the physicochemical origins of this preference via quantum chemical calculations. The computational results show that all enthalpies and free energies for adsorption of DEG onto the CILS clusters are lower for the positively charged seeds compared to the negatively charged seeds. The main reason for this difference is the stronger hydrogen bonds in the cationic clusters originated from the ability of imidazolium-based cations in acting as a hydrogen bond acceptors. 


\section{INTRODUCTION}

Heterogeneous nucleation is a phase change process in which a new phase forms onto an existing seed. These processes are important for example in material sciences ${ }^{1-4}$, in atmospheric cloud and ice nuclei formation ${ }^{5-7}$ and for fundamental understanding of physics and chemistry ${ }^{8-10}$. In the specific case of gas-to-particle conversion, new solid particles or liquid droplets form via heterogeneous nucleation and subsequent condensation of vapors. Heterogeneous nucleation is governed by the interactions between the seed and the condensing vapor, which are affected by the size, charging state and chemical composition of the seed ${ }^{11-14}$, the supersaturation and chemical composition of the vapor ${ }^{15-16}$, and nucleation temperature ${ }^{17-18}$.

Classical theoretical treatment of heterogeneous nucleation is based on the Kelvin equation for neutral seeds, and the Kelvin-Thomson model for charged seeds. The latter model does not distinguish between positive and negative charges . Both theories incorporate bulk properties of the seeds and vapor to treat molecular-level processes. Several experiments have tested these theories, often finding the critical supersaturation required for a chosen threshold particle formation rate to be lower than the theoretically predicted one ${ }^{16,18-24}$. On the other hand, Tauber, et al. ${ }^{14}$ has reported ion-induced nucleation experiments on singly charged atoms, which follow well the Kelvin-Thomson prediction.

An unresolved question in the process of heterogeneous nucleation are the interlinked roles of electric charge and seed chemical composition. More than hundred years ago, Wilson ${ }^{25}$ conducted cloud chamber experiments by condensing water vapor onto unipolar ionic seeds, noting that cloud formation takes place more readily when negative ions are present in the chamber compared to positive ions. This observation has been called "negative sign preference". After Wilson, several experiments reported negative or positive sign preferences in various systems. In some of them, small ions were produced in a chamber, and the number of nucleated particles was counted after the ions were exposed to supersaturated vapor ${ }^{26-31}$. Such techniques lack control over ion size as well as seed chemistry. Other experiments produced ions of controlled size and charging state using differential 
mobility analysis (DMA), and probed the heterogeneous nucleation probability as a function of seed size. Also such experiments have reported more significant seed activation at constant seed size at one polarity compared to the other polarity, indicative of sign preference ${ }^{14,22-23,32-34}$.

The effect of the vapor chemical composition has been studied more than the chemical composition of the seed likely due to the lack of experimental and computational methods capable of treating the complexity of the seed accurately. By using mass spectrometric techniques for seed characterization, it was recently shown that seeds formed from the same source material but with different polarities do not necessarily have the same chemical composition because of the presence of impurities, and/or differences in the chemical reactions forming them ${ }^{35-36}$. This observation highlights the challenge of distinguishing the effect of seed composition from that of the charging state without direct measurement of the cluster composition, as discussed also in the theoretical study of Kathmann, et al. ${ }^{37}$. Other theoretical examinations of sign preference have, for example, found that negative pure water clusters nucleate more readily than the positive ones ${ }^{38}$ while sulfuric acid-water clusters display a strong negative sign preference ${ }^{39}$. The latter can be explained in terms of acid-base interactions: strong acids such as sulfuric acid prefer anionic clusters, since anions act as bases ${ }^{40}$. What is quite well experimentally established is that charged seeds, especially at cluster sizes of few nm, are generally preferred over neutral seeds for nucleation ${ }^{11-12,41}$ - though computational studies suggest a few exceptions even to this rule: for example $\mathrm{H}_{2} \mathrm{SO}_{4}$ prefers neutral amines over protonated aminium cations ${ }^{40}$ - again because of greater basicity of the neutral molecule. Apart from these exceptional cases of strong acids and/or strong bases, our understanding of the molecular origins behind the sign preferences observed for specific chemistries and charging states, especially in complex systems, remains limited.

Here we explain the experimentally observed heterogeneous nucleation sign preference of a chemically complex system through first principles quantum chemical modeling. We study the first steps of diethylene glycol (DEG) nucleation on singly charged clusters of 1-butyl-3-methyl 
imidazolium tetraboroflorate $\quad\left(\mathrm{C}_{8} \mathrm{~N}_{2} \mathrm{H}_{15} \mathrm{BF}_{4}, \quad \mathrm{BMIBF}_{4}\right), \quad$ 1-ethyl-3-methylimidazolium tris(pentafluoroethyl)trifluorophosphate $\quad\left(\mathrm{C}_{6} \mathrm{~N}_{2} \mathrm{H}_{11}\left(\mathrm{C}_{2} \mathrm{~F}_{5}\right)_{3} \mathrm{PF}_{3}, \quad\right.$ EMIFAP) $\quad$ and 1-ethyl-3methylimidazolium trifluoromethanesulfonate $\left(\mathrm{C}_{6} \mathrm{~N}_{2} \mathrm{H}_{11} \mathrm{CF}_{3} \mathrm{SO}_{3}\right.$, EMITFMS) ionic liquids (ILs; Figure $\mathrm{S} 1$ ) of the $(\mathrm{AC}) \mathrm{n}^{-}$or $(\mathrm{AC})_{\mathrm{n}} \mathrm{C}^{+}$type (A: anion; and $\mathrm{C}$ : cation). We have selected this system for our theoretical study, as the exact chemical composition of these clusters can be determined experimentally.

\section{METHODS}

Experimental Measurement. To generate the seeds, the ILs were dissolved in methanol and the resultant $20 \mathrm{mM}$ solutions were electrosprayed using a bipolar electrospray source (Fernandez de la Mora and Barrios-Collado 2017). The two needles were flushed with particle free compressed air at the flow rate of $6 \mathrm{~L} \mathrm{~min}^{-1}$, the mobilities and cross sections were measured in air at $101325 \mathrm{~Pa}$ and $298 \mathrm{~K}$. The generated polydisperse cloud of ions in the sample flow was guided into a Half-mini ptype differential mobility analyzer (DMA; Fernandéz de la Mora 2017) to separate a close to monomobile unipolar ion distribution from the initial sample. The absolute ion concentration was measured downstream of the DMA using an aerosol electrometer with a flow rate of $2.5 \mathrm{~L} \mathrm{~min}^{-1}$, and parallel to that the flow reactor was operated with an equal inlet flow of $2.5 \mathrm{~L} \mathrm{~min}^{-1}$. The reactor was a two-stage commercial mixing type condensation particle counter Airmodus A11 (Vanhanen et al. 2011), typically called a particle size magnifier (PSM). In the first stage, the aerosol flow was adiabatically and turbulently mixed with a heated flow that was saturated with diethylene glycol DEG to create DEG supersaturation. The operational temperatures were as follows: saturator $82^{\circ} \mathrm{C}$, growth tube $2{ }^{\circ} \mathrm{C}$ and inlet $40{ }^{\circ} \mathrm{C}$. The DEG flow rate was scanned from 0.1 to $1.3 \mathrm{~L} \mathrm{~min}^{-1}$ to vary the supersaturation level. The particles that were grown by DEG reached the size of about $90 \mathrm{~nm}$, and they were further enlarged by butanol condensation and finally counted by an optical detector. The supersaturation level of the reactor was scanned in a 2-min cycle for each selected ion mobility from 
$0 \%$ to $100 \%$ activation probability. The described experimental setup is schematically shown in Figure S2. To plot Figures 2 and 3, the data were selected to present just the clusters with activation probabilities close to $100 \%$ at the highest supersaturation (filtering out the very small clusters), and no background counts detected at the lowest supersaturation originating likely from multiply charged ions overlapping with the sample clusters (filtering out the large clusters).

Because of the complex structure of the reactor, exact determination of the supersaturation level was uncertain, and we used the flow mixing ratio, calculated as $Q_{s} /\left(Q_{s}+Q_{a}\right)$, where $Q_{s}$ is the saturated flow rate and $Q_{a}$ the aerosol flow rate, as a trace for supersaturation. This is sufficient for examining the sign preference. The heterogeneous nucleation probability was obtained as the ratio of particle concentration detected by the PSM to the concentration detected by the aerosol electrometer. The critical flow mixing ratio required for nucleation was determined as the flow mixing ratio giving $50 \%$ probability of heterogeneous nucleation. The critical mixing ratio was measured for CILS filling the two previous criteria (of ca. $100 \%$ nucleation probability and detection of no background counts) for both polarities of the three ILs by varying the selected mobility in the mobility analyzer. Sign preference was identified as the smaller critical mixing ratio between positive and negative seeds.

The classification voltages of the DMA were translated to collision cross sections (CCSs) using the Mason-Schamp equation

$\operatorname{CCS}=\frac{3}{16} \sqrt{\frac{2 \pi}{\mu k_{B} T}} \frac{z e}{N_{0} Z_{0}}$

where $\mu=m_{i} m_{g} /\left(m_{i}+m_{g}\right)$ is the reduced mass, $k_{B}$ is Boltzmann's constant, $T$ is temperature $(298 \mathrm{~K}), z$ is the charging state, $e$ is unit charge, $N_{0}$ is Loschmidt number and $Z_{0}$ is the reduced mobility given by

$Z_{0}=Z \frac{p}{p_{0}} \frac{T_{0}}{T}$ 
where $T_{0}$ is $273.15 \mathrm{~K}, T$ is $298 \mathrm{~K}, p_{0}$ is $100000 \mathrm{pa}, p$ is $101325 \mathrm{pa}$, and $Z$ is the measured mobility. The voltages were translated into mobility using the relation $V_{l} / V_{r e f}=\left(1 / Z_{1}\right) /\left(1 / Z_{r e f}\right)$, where $Z_{r e f}$ is the mobility of the $\mathrm{EMI}^{+}$ion taken from Larriba, et al. ${ }^{42}$, and $V_{\text {ref }}$ is the peak voltage measured for the $\mathrm{EMI}^{+}$ion in our measurements.

Computational Modeling. The initial steps of the heterogeneous nucleation process of charged (AC) $\mathrm{A}^{-}$and $(\mathrm{AC}) \mathrm{C}^{+}$clusters with two cations or anions of the same ionic liquids as in the experiments were modelled by DFT calculations at the $\omega$ B97X-D/6-31+g(d) and $\omega$ B97X-D/def2TZV levels by Gaussian 16 (ref. ${ }^{43}$ ). Our working hypothesis is that the results obtained for the (AC) $\mathrm{A}^{-}$and (AC) $\mathrm{C}^{+}$ clusters can shed light on the mechanism of the nucleation process over the whole range of cluster sizes, as the individual vapor-seed interactions are likely to be similar. A corollary hypothesis is that the adsorption of the first few DEG molecules similarly provides at least qualitative insights into the overall DEG condensation process, including especially the relative differences between seeds of different composition and charge state. This hypothesis is based on the fact that if the binding of the first few vapor molecules to a seed of some particular polarity is very weak, then the seed in question will never nucleate, as the molecules will always evaporate before further vapor molecules collide with the seed. Also, the formation free energy of the critical cluster is ultimately determined by the same types of chemical interactions (seed-vapor, vapor-vapor) already present in the small clusters with 2-3 vapor molecules. Thus, if enormous differences are found in the favorability of adsorption of the first vapor molecules to two different seeds, this will inevitably translate into a large difference also between the corresponding critical clusters. Therefore, the association of the first few vapor molecules with two different seeds is sufficient for determining the relative supersaturations required for heterogeneous nucleation onto those two seeds. Furthermore, this hypothesis has been previously demonstrated acceptable e.g. for the case of water condensation onto charged sulfuric acid clusters, ${ }^{39}$ and is also supported by the similarities in the trends of the adsorption energies for the first three DEG molecules, as discussed in the results. Quantitative modelling of the heterogeneous nucleation rate or 
probability would require that the simulated set of clusters includes the critical cluster - which is often rendered impossible by computational limitations. As the number of DEG molecules in the critical cluster (for a given seed) depends on the supersaturation, this criterion is met for some supersaturations even for our relatively small cluster dataset. However, as we cannot directly quantify the experimental supersaturation in our setup, a quantitative comparison of modelled and experimental rates is in any case outside the scope of this study.

The first steps of heterogeneous nucleation were modelled by calculating the enthalpies and Gibbs free energies of DEG adsorption onto the clusters. Due to the presence of multiple low-lying vibrational modes, the quasi-harmonic approximation ${ }^{44-46}$ was used to correct for the errors in the standard rigid rotor - harmonic oscillator approximation [see section SA]. Since the rate of vapor evaporation from the clusters depends exponentially on the adsorption free energy (with lower free energies giving slower evaporation), the free energy is directly related to heterogeneous nucleation probability. In particular, if the free energy of adsorption of the first few DEG molecules to some seed are too high, leading to high evaporation rates compared to the collision rates corresponding to some given supersaturation, heterogeneous nucleation will not occur. Differences in adsorption energies of the first few vapor molecules between anion and cation seeds of similar size may thus be linked to the experimentally observed sign preferences. Full details of the calculations can be found in Section SA of the supporting information.

Briefly, the calculations started with computational level validation (Figure S3) and conformational/configurational analysis of EMI, BMI and FAP. We used the lowest-energy gasphase conformer of DEG in the simulations. While this introduces a minor uncertainty, we note that this conformer is well-suited for adsorption, as it has both $\mathrm{OH}$ groups on the same side (see Figure S5), and is able to bond to a seed. After selection of several representative anion and cation conformers/configurations (see Figure S4), a systematic configurational sampling technique ${ }^{47}$ was used to create a total of 16 charged ionic liquid seeds (CILSs; see Section SB about their 
conformational diversity) and CILS-DEG clusters. In this technique, a large set of seed and seedDEG configurations was generated using low-cost calculations. Then, the structures were optimized at a higher level of theory and filtered based on their uniqueness and energy profiles. The reoptimization and filtering steps were repeated until we reached the global minimum structure for each cluster. After that, natural bond-orbital (NBO) analysis was performed to understand the bonding patterns of the most stable CILS-DEG clusters.

In the end, we selected the lowest energy CILSs from the quantum chemical calculations, and calculated their collision cross section (CCS) using the Ion Mobility Software ${ }^{48-49}$, which models the drag force induced by the ion-neutral collisions. In the IMOS software, we used the trajectory method with Lennard-Jones potentials and quadrupole interactions included in the collisions, using the CHelpG partial charges (CHarges from electrostatic potentials using a grid based method) calculated at the $\omega$ B97X-D/def2TZV level and listed in Section SC. In IMOS, the Lennard-Jones potentials have been optimized against experiments only for the collisions with $\mathrm{N}_{2}$ molecules ${ }^{50}$, therefore we ran the CCS simulation both in $\mathrm{N}_{2}$ and air (which was the carrier gas in our experiments but for which the LJ have not been optimized). We report only the results with $\mathrm{N}_{2}$ as the modeled CCSs are closer to the experimental CCS as compared to CCS modeled in air with unoptimized LJ parameters. The CCS values of the modeled CILSs were directly compared to the measured CCSs at $273 \mathrm{~K}$ and $100000 \mathrm{~Pa}$, allowing us to both validate our structural results, and also connect the modelling results on DEG absorption to a particular size range of seeds studied in the experiments.

\section{RESULTS AND DISCUSSION}

Figure 1 presents the mobility spectrum of the positively and negatively charged EMITFMS seeds. The signals from the individual clusters are well separated in the mobility space, and we can thus assume that the cluster populations downstream of the DMA consist of only one cluster type. At 
around 700-800 $\mathrm{V}$ and larger voltages the oscillating signals increasingly deviate from 0 a.u., suggesting some contribution of multiply charged droplets to the measured signals. Table 1 lists the reduced mobilities $Z_{0}$ and CCSs for the ten smallest ions for each sample.

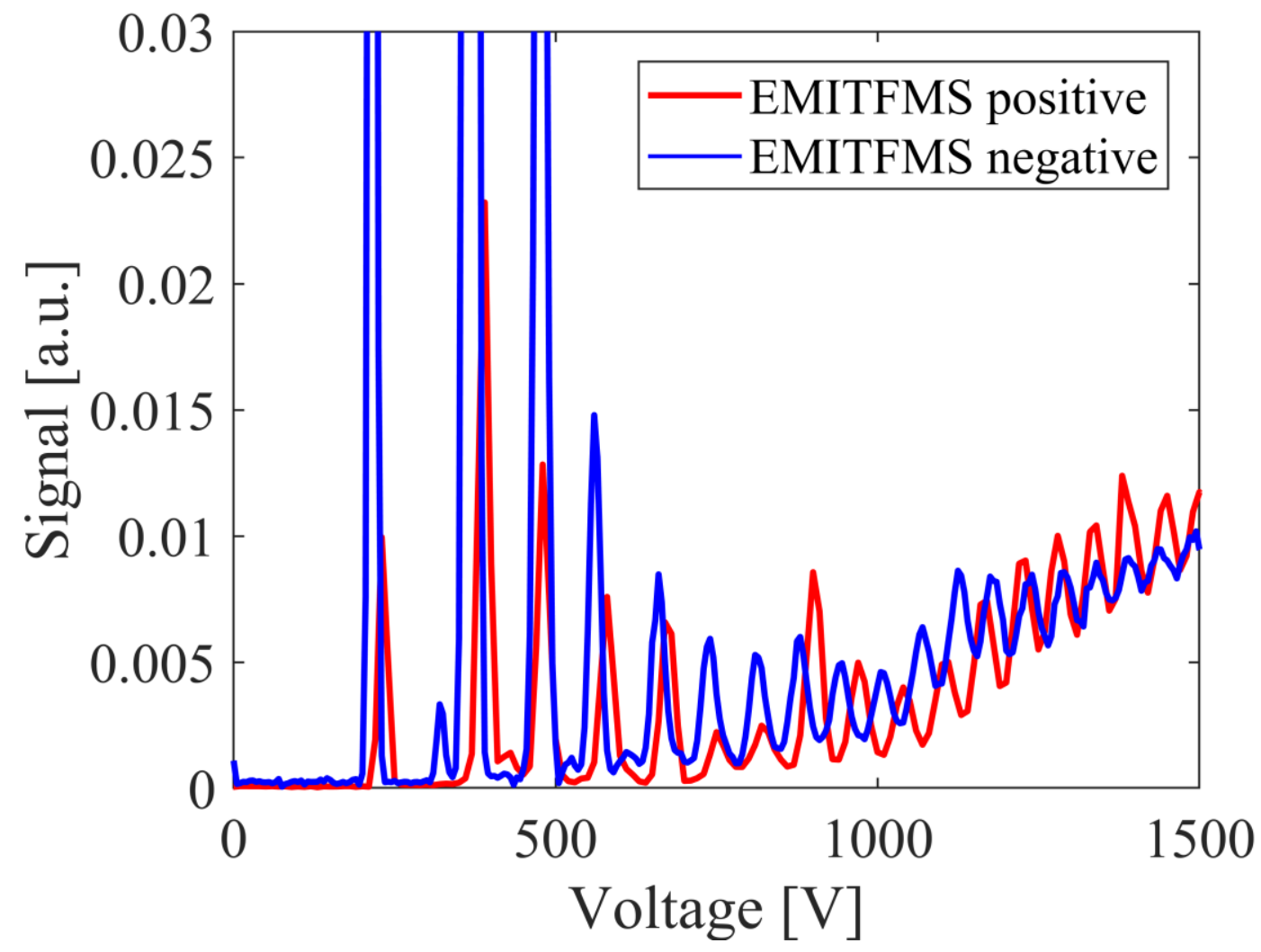

Figure 1. Mobility spectrum of EMITFMS 
Table 1. Experimental masses, reduced mobilities $\left[Z_{0}, \mathrm{~cm}^{2} \mathrm{~V}^{-1}\right]$ and CCSs $\left[\AA^{2}\right]$ for the ten smallest CILSs of each sample, based on DMA classification voltages. An ion pair number $n$ corresponds to anions of the type $(\mathrm{AC})_{\mathrm{n}} \mathrm{A}^{-}$and cations of the type $(\mathrm{AC})_{\mathrm{n}} \mathrm{C}^{+}$.

\begin{tabular}{|c|c|c|c|c|c|c|}
\hline \multirow{2}{*}{$\begin{array}{l}\text { Ion } \\
\text { pair }\end{array}$} & \multicolumn{3}{|c|}{$\mathrm{BMIBF}^{-}$} & \multicolumn{3}{|c|}{$\mathrm{BMIBF}^{+}$} \\
\hline & Mass & $\mathrm{CCS}$ & $Z_{0}$ & Mass & CCS & $Z_{0}$ \\
\hline 0 & 87.00 & 108.44 & 2.12 & 139.12 & 127.82 & 1.71 \\
\hline 1 & 313.13 & 172.95 & 1.20 & 365.25 & 190.49 & 1.09 \\
\hline 2 & 539.26 & 215.76 & 0.95 & 591.38 & 233.59 & 0.87 \\
\hline 3 & 765.38 & 255.13 & 0.79 & 817.50 & 273.03 & 0.74 \\
\hline 4 & 991.51 & 299.43 & 0.67 & 1043.63 & 317.35 & 0.64 \\
\hline 5 & 1217.63 & 334.84 & 0.60 & 1269.76 & 348.24 & 0.58 \\
\hline 6 & 1443.76 & 370.36 & 0.54 & 1495.88 & 379.26 & 0.53 \\
\hline 7 & 1669.89 & 401.44 & 0.50 & 1722.01 & 414.86 & 0.48 \\
\hline 8 & 1896.01 & 432.57 & 0.46 & 1948.13 & 446.00 & 0.45 \\
\hline \multirow[t]{3}{*}{9} & 2122.14 & 463.74 & 0.43 & 2174.26 & 472.67 & 0.42 \\
\hline & \multicolumn{3}{|c|}{ EMIFTMS- } & \multicolumn{3}{|c|}{ EMIFTMS $^{+}$} \\
\hline & Mass & $\mathrm{CCS}$ & $Z_{0}$ & Mass & CCS & $Z_{0}$ \\
\hline 0 & 148.95 & 117.57 & 1.85 & 111.09 & 115.51 & 1.93 \\
\hline 1 & 409.00 & 185.17 & 1.11 & 371.14 & 181.09 & 1.14 \\
\hline 2 & 669.04 & 223.85 & 0.91 & 631.18 & 224.10 & 0.91 \\
\hline 3 & 929.08 & 263.40 & 0.77 & 891.22 & 263.55 & 0.77 \\
\hline 4 & 1189.13 & 307.78 & 0.65 & 1151.27 & 303.36 & 0.66 \\
\hline 5 & 1449.17 & 347.77 & 0.58 & 1411.31 & 338.82 & 0.59 \\
\hline 6 & 1709.22 & 374.31 & 0.54 & 1671.36 & 369.86 & 0.54 \\
\hline 7 & 1969.26 & 409.93 & 0.49 & 1931.40 & 405.48 & 0.49 \\
\hline 8 & 2229.31 & 441.09 & 0.45 & 2191.45 & 436.63 & 0.46 \\
\hline
\end{tabular}




\begin{tabular}{|c|c|c|c|c|c|c|}
\hline & \multicolumn{3}{|c|}{ EMIFAP- $^{-}$} & \multicolumn{3}{|c|}{ EMIFAP $^{+}$} \\
\hline & Mass & CCS & $Z_{0}$ & Mass & $\mathrm{CCS}$ & $Z_{0}$ \\
\hline 0 & 444.95 & 150.67 & 1.36 & 111.09 & 115.51 & 1.93 \\
\hline 1 & 1000.98 & 249.05 & 0.81 & 667.13 & 210.13 & 0.97 \\
\hline 2 & 1557.02 & 318.11 & 0.63 & 1223.17 & 305.48 & 0.66 \\
\hline 3 & 2113.06 & 374.14 & 0.54 & 1779.20 & 411.40 & 0.49 \\
\hline 4 & 2669.09 & 440.32 & 0.45 & 2335.24 & 474.05 & 0.42 \\
\hline 5 & 3225.13 & 489.91 & 0.41 & 2891.28 & 560.18 & 0.36 \\
\hline 6 & 3781.17 & 539.54 & 0.37 & 3447.32 & 599.71 & 0.33 \\
\hline 7 & 4337.21 & 585.88 & 0.34 & 4003.35 & 639.32 & 0.31 \\
\hline 8 & 4893.24 & 625.59 & 0.32 & 4559.39 & 682.31 & 0.29 \\
\hline 9 & 5449.28 & 668.65 & 0.30 & 5115.43 & 722.00 & 0.28 \\
\hline
\end{tabular}

Figure 2 presents the activated fraction of the EMITFMS clusters in the flow reactor as a function of the DEG mixing ratio. Large open circles are the $n=1$ clusters which are further modeled for DEG adsorption. We can observe that as expected, the larger clusters are activated at lower mixing ratios, and that the positively charged clusters require smaller mixing ratios to be activated relative to the negative clusters of similar CCS (compare for example the open circle symbols for clusters with CCSs of 303 and $307 \AA^{2}$ ). This observation can be interpreted as positive sign preference in our IL-DEG system, and is observed for the three different IL samples. From these data we infer the critical mixing ratio for each cluster as the mixing ratio at which the activation probability is $50 \%$. 


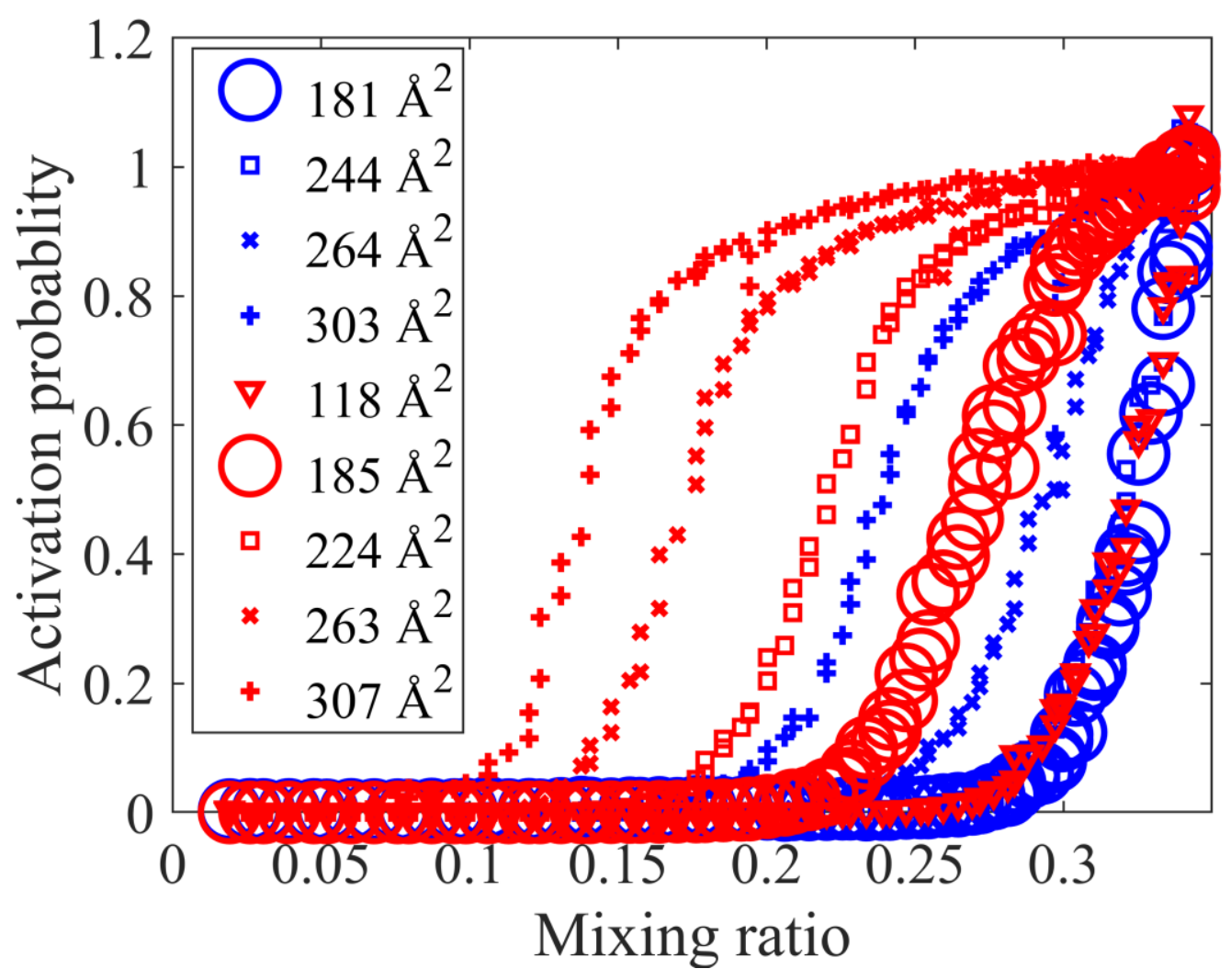

Figure 2. Activation probability as function of the flow mixing ratio for EMITFMS. Red data is for positive and blue for negative clusters. Large open circles are the clusters $(n=1)$ for which vapor adsorption modeling is conducted.

Figure 3 collects the critical mixing ratios for each cluster type plotted against the experimental CCSs, while Table 2 verifies the structures of the modeled CILSs by comparing the experimental and modeled CCSs and giving the maximal CCS difference of $7.31 \%$, and Table 3 reports the nucleation modeling results. In Table 3, the positively and negatively CILSs contain the name of the base ionic liquid and the second anion/cation, in addition to the total charge of the seed. Similar CILSs with different cation/anion conformational/configurational compositions are distinguished by numbering them based on their Gibbs free energy $(\Delta G)$ of formation $(\omega b 97 \mathrm{X}-\mathrm{D} / \mathrm{def} 2 \mathrm{TZVP}$ level; neglecting the quasi-harmonic treatment). For instance, among the three negatively charged EMIFAP seeds, (EMIFAP)FAP'-1 and (EMIFAP)FAP-3 are the most and least stable seeds, respectively. 


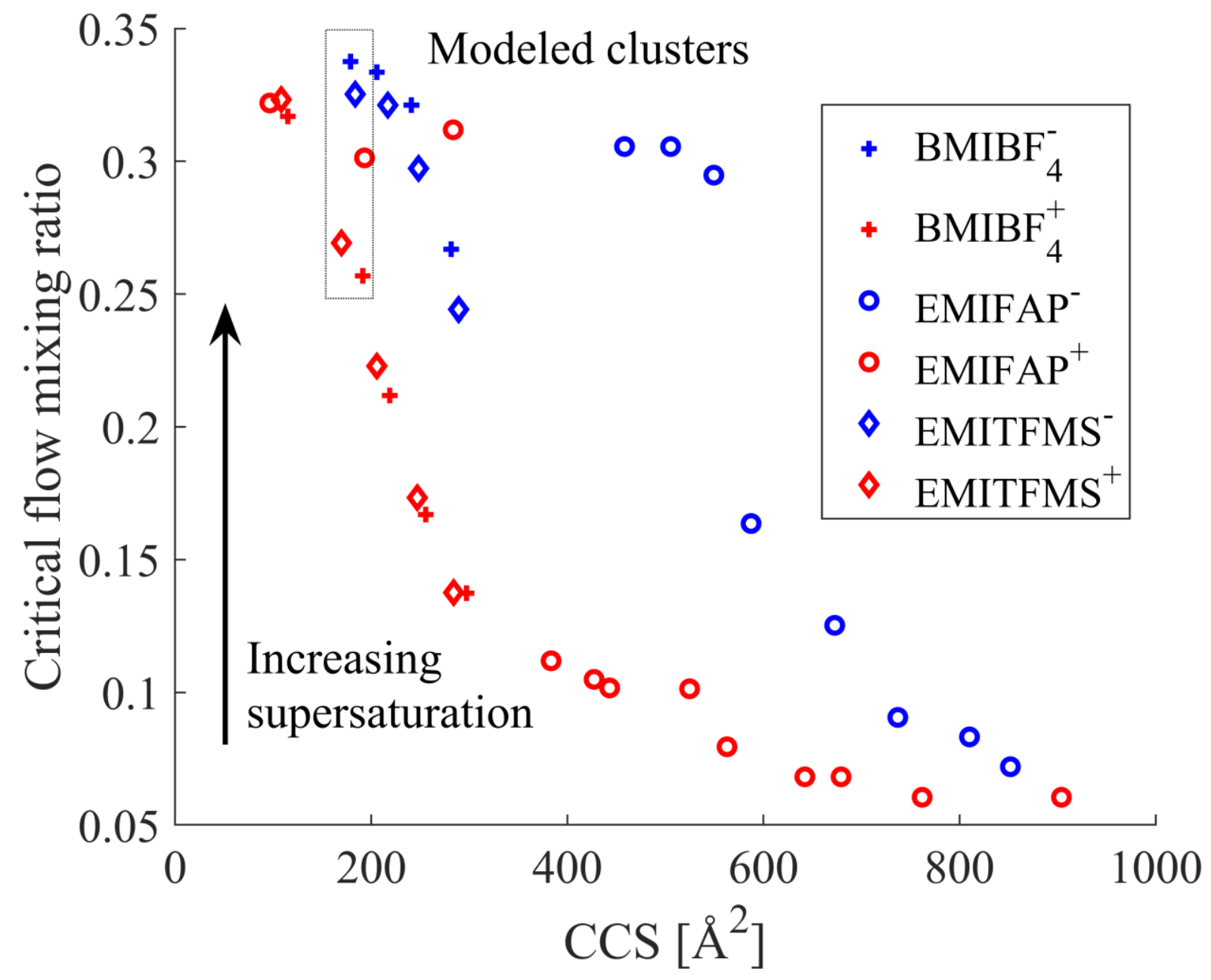

Figure 3. DEG flow mixing ratios of the CILSs as a function of the clusters' CCSs. Also negative EMIFAP with $n=1$ was modeled even though heterogeneous nucleation was not observed for it in our experimental conditions.

Table 2. Experimental and modeled CCS $\left[\AA^{2}\right]$, and difference of the modelled value relative to the experimental value [\%] for CILS clusters of the type (AC) $\mathrm{A}^{-}$and $(\mathrm{AC})_{\mathrm{n}} \mathrm{C}^{+}$.

\begin{tabular}{lcccccc}
\hline & BMIBF4 $^{-}$ & BMIBF4 $^{+}$ & EMIFTMS & EMIFTMS $^{+}$ & EMIFAP $^{-}$ & EMIFAP $^{-}$ \\
\cline { 2 - 7 } Model & 173.71 & 193.73 & 186.82 & 190.79 & 249.68 & 225.49 \\
Experiment & 172.95 & 190.49 & 185.17 & 181.09 & 249.05 & 210.13 \\
Difference & 0.44 & 1.70 & 0.89 & 5.36 & 0.25 & 7.31 \\
\hline
\end{tabular}


At constant CCS, a smaller DEG mixing ratio is required for heterogeneous nucleation onto the positive seeds compared to the negative ones for all CILS sizes and compositions, clearly exhibiting positive sign preference in our test systems. The computed thermodynamics parameters in Table 3 generally support this, as the $\Delta G$ values clearly indicate that DEG prefers adsorption on the positively charged EMITFMS and BMIBF4 seeds. In the case of EMIFAP, the adsorption energy $(\Delta E)$, enthalpy $(\Delta H)$ and $\Delta G$ values indicate only slight positive seed preference while the experiments suggest EMIFAP shows the highest difference in mixing ratio at constant CCS (i.e. the strongest sign preference). Note worthily, EMIFAP was quite computationally demanding and its harmonic frequency calculations yielded many low frequencies and a few imaginary vibrations (which were eliminated as described in Section SA of the supporting information). Therefore, the reliability of our computations is lower for EMIFAP, and the EMIFAP results are more sensitive to quasi-harmonic corrections relative to the EMITFMS and BMIBF4 CLISs.

Table 3. Thermodynamics of one DEG molecule adsorption considering quasi-harmonic correction (see section $\mathrm{SB}$ ), at $298.15 \mathrm{~K}$. The $\Delta E, \Delta H$ and $\Delta G$ values are in $\mathrm{kJ} \mathrm{mol}^{-1}$ while the $\Delta S$ values are in $\mathrm{J} \mathrm{mol}^{-1}$. The bolded, italicized and underlined values respectively highlight the most efficient seeds for DEG nucleation based on the $\Delta G, \Delta H$ and $\Delta E$ criteria.

\begin{tabular}{|c|c|c|c|c|c|c|c|c|}
\hline \multirow[b]{2}{*}{ CILS } & \multicolumn{4}{|c|}{$\omega b 97 X-D / 6-31+G^{*}$} & \multicolumn{4}{|c|}{$\omega b 97 X-D / d e f 2 T Z V P$} \\
\hline & $\Delta E$ & $\Delta H$ & $\Delta G$ & $\Delta S$ & $\Delta E$ & $\Delta H$ & $\Delta G$ & $\Delta S$ \\
\hline (EMITFMS)TFMS- & $\underline{-94.0}$ & -95.9 & -28.4 & -226.5 & $\underline{-83.1}$ & -83.7 & -17.9 & -220.5 \\
\hline (EMITFMS)EMI $^{+}$ & $\underline{-104.9}$ & -105.3 & -43.4 & -207.4 & $\underline{-102.0}$ & -102.8 & -34.6 & -228.8 \\
\hline (BMIBF4)BF4-1 & -86.8 & -87.7 & -24.2 & -212.8 & -84.9 & -85.6 & -19.5 & -221.8 \\
\hline (BMIBF4)BF4-2 & $\underline{-105.4}$ & -109.3 & -37.0 & -242.3 & $\underline{-89.7}$ & -90.5 & -21.3 & -232.0 \\
\hline (BMIBF4)BF4-3 & -85.3 & -86.2 & -23.6 & -209.9 & -82.1 & -82.3 & -19.5 & -210.6 \\
\hline (BMIBF4)BMI ${ }^{+} 1$ & -87.0 & -87.9 & -22.9 & -217.9 & -82.9 & -83.9 & -15.6 & -228.8 \\
\hline
\end{tabular}




\begin{tabular}{|c|c|c|c|c|c|c|c|c|}
\hline (BMIBF4)BMI+-2 & -82.6 & -84.8 & -16.6 & -228.8 & -80.4 & -81.5 & -13.5 & -228.0 \\
\hline$(\mathrm{BMIBF} 4) \mathrm{BMI}^{+}-3$ & -91.8 & -93.8 & -26.1 & -226.8 & -87.1 & -87.2 & -22.4 & -217.4 \\
\hline (BMIBF4)BMI ${ }^{+}-4$ & -88.8 & -90.3 & -22.6 & -227.0 & -86.4 & -86.7 & -19.5 & -225.6 \\
\hline$(\mathrm{BMIBF} 4) \mathrm{BMI}^{+}-5$ & $\underline{-104.9}$ & -106.5 & -40.2 & -222.2 & $\underline{-98.8}$ & -99.7 & -31.9 & -227.5 \\
\hline$(\mathrm{BMIBF} 4) \mathrm{BMI}^{+}-6$ & -97.2 & -98.3 & -32.1 & -222.2 & -92.7 & -92.7 & -27.4 & -219.1 \\
\hline (EMIFAP)FAP'-1 & -62.5 & -61.9 & -0.2 & -206.9 & $\underline{-72.8}$ & -71.6 & -8.7 & -211.1 \\
\hline (EMIFAP)FAP'-2 & $\underline{-74.6}$ & -73.9 & -14.2 & -200.0 & -71.6 & -72.5 & -3.6 & -231.2 \\
\hline (EMIFAP)FAP'-3 & -65.4 & -64.9 & -3.8 & -205.0 & -66.2 & -66.1 & -0.9 & -218.6 \\
\hline (EMIFAP)EMI ${ }^{+}-1$ & $\underline{-79.2}$ & -78.9 & -15.6 & -212.3 & $\underline{-74.0}$ & -73.0 & -9.2 & -214.0 \\
\hline (EMIFAP)EMI ${ }^{+}-2$ & -77.9 & -80.3 & -12.1 & -228.7 & -69.6 & -68.5 & -4.2 & -215. \\
\hline
\end{tabular}

To uncover the actual molecular-level interactions behind the patterns seen in Figure 3 and Table 3, we performed NBO analysis. Table 4 shows the key results of this analysis: $E^{(2)}$ is second-order perturbation energy which quantifies the strength of various donor-acceptor interactions. As indicated by Table 4 and Figure S6, the main type of interaction that drives DEG adsorption is hydrogen bonding between the hydroxyl groups of DEG and the CILS ions. The hydrogen bonding interactions are represented by charge transfer from the lone pair orbital (LP) of an electronegative atom ( $\mathrm{O}$ and $\mathrm{F}$ atoms, here) to the antibonding orbital $\left(\sigma^{*}\right)$ of a hydrogen bond acceptor $(\mathrm{OH}$ and $\mathrm{CH})$. In line with the thermodynamic results, the positively charged seeds can establish stronger hydrogen bonding networks with more hydrogen bonds relative to their negatively charged forms. This is somewhat surprising and counterintuitive, since simple (e.g. monoatomic) anions are typically better hydrogen bond acceptors than simple cations. This would likely be the case for the isolated EMI/BMI cations and TFMS/BF4/FAP anions alone - however their composite clusters behave differently. For the EMITFMS and BMIBF4 clusters, DEG actually prefers to bind to the anionic constituents of the clusters partly because $\mathrm{LP}(\mathrm{F})$ to $\sigma^{*}(\mathrm{OH})_{\mathrm{DEG}}$ hydrogen bonding is very effective in DEG adsorption on BMIBF4 and influential on DEG(EMIFAP)EMI ${ }^{+}-1$ cluster formation. However, the cations act to stabilize the binding by providing more hydrogen bond acceptors (making the H-bonding network stronger), leading to a positive sign preference. 
In the case of EMIFAP, DEG actually prefers to adsorb on the cationic constituents because of FAP's inefficiency in acting as a hydrogen bonding acceptor, which results in the low potency of negative EMIFAP seeds for DEG adsorption. Moreover, the larger size of the FAP anion limits its adsorption ability, relative to the BF4 and TFMS anions, which is consistent with the observations of Maisser and Hogan ${ }^{51}$, whose ion mobility measurements indicated that smaller ions are more efficient in the formation of ionvapor complexes between n-butanol and the $\mathrm{K}^{+}, \mathrm{Rb}^{+}, \mathrm{Cs}^{+}, \mathrm{Br}^{-}$, and $\mathrm{I}^{-}$ions under sub-saturated conditions. Nevertheless, while the ether oxygen of DEG is not involved in DEG adsorption onto EMITFMS and BMIBF4, it assists DEG stabilization over the EMIFAP's cationic constitutes.

Table 4. Summary of the second-order perturbation energies $\left(E^{(2)}\right.$ stabilization energy; $\left.\mathrm{kJ} \mathrm{mol}^{-1}\right)$ related

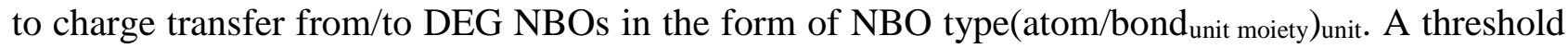
of $1 \mathrm{kcal} \mathrm{mol}^{-1}\left(=4.2 \mathrm{~kJ} \mathrm{~mol}^{-1}\right)$ has been used (i.e. interactions with smaller perturbation energies are not reported). The units and unit moieties are numbered to make them distinguishable. "cyc" represents the imidazolium ring of EMI and BMI. The ether and hydroxyl oxygen atoms of DEG are distinguished as $\mathrm{O}_{\mathrm{OH}}$ and $\mathrm{O}_{\mathrm{O}}$, respectively.

\begin{tabular}{|c|c|c|c|c|c|}
\hline From & To & $E^{(2)}$ & From & To & $E^{(2)}$ \\
\hline \multicolumn{3}{|c|}{ (EMITFMS)EMI ${ }^{+}$} & \multicolumn{3}{|c|}{ (EMITFMS)TFMS ${ }^{-}$} \\
\hline $\mathrm{LP}\left(\mathrm{O}_{\mathrm{OH}-1}\right)_{\mathrm{DEG}}$ & $\sigma^{*}\left(\mathrm{CN}_{\mathrm{cyc}-2}\right)_{\mathrm{EMI}-1}$ & 4.4 & $\mathrm{LP}\left(\mathrm{O}_{\mathrm{OH}-1}\right)_{\mathrm{DEG}}$ & $\sigma^{*}\left(\mathrm{CH}_{\mathrm{cyc}-1}\right)_{\mathrm{EMI}}$ & 20.7 \\
\hline $\mathrm{LP}\left(\mathrm{O}_{\mathrm{OH}-2}\right)_{\mathrm{DEG}}$ & $\sigma^{*}\left(\mathrm{CH}_{\mathrm{cyc}-0}\right)_{\mathrm{EMI}-2}$ & 23.5 & $\mathrm{LP}\left(\mathrm{O}_{\mathrm{OH}-1}\right)_{\mathrm{DEG}}$ & $\sigma^{*}\left(\mathrm{CH}_{\mathrm{cyc}-1}\right)_{\mathrm{EMI}}$ & 5.1 \\
\hline $\mathrm{LP}\left(\mathrm{O}_{\mathrm{OH}-2}\right)_{\mathrm{DEG}}$ & $\sigma^{*}\left(\mathrm{CH}_{\text {ethyl-1 }}\right)_{\text {EMI-2 }}$ & 5.3 & $\mathrm{LP}\left(\mathrm{O}_{\mathrm{OS}-2}\right)_{\mathrm{TFMS} 2}$ & $\sigma^{*}\left(\mathrm{OH}_{\mathrm{OH}-2}\right)_{\mathrm{DEG}}$ & 48.6 \\
\hline $\mathrm{LP}\left(\mathrm{O}_{\mathrm{OS}-1}\right)_{\mathrm{TFMS}}$ & $\sigma^{*}\left(\mathrm{OH}_{\mathrm{OH}-1}\right)_{\mathrm{DEG}}$ & 11.8 & $\mathrm{LP}\left(\mathrm{O}_{\mathrm{OS}-3}\right)_{\mathrm{TFMS} 2}$ & $\sigma^{*}\left(\mathrm{CH}_{\mathrm{CH}-2}\right)_{\mathrm{DEG}}$ & 4.4 \\
\hline $\mathrm{LP}\left(\mathrm{O}_{\mathrm{OS}-1}\right)_{\mathrm{TFMS}}$ & $\sigma^{*}\left(\mathrm{OH}_{\mathrm{OH}-2}\right)_{\mathrm{DEG}}$ & 9.2 & $\sigma^{*}\left(\mathrm{OS}_{\mathrm{OS}-2}\right)_{\mathrm{TFMS} 2}$ & $\sigma^{*}\left(\mathrm{OH}_{\mathrm{OH}-2}\right)_{\mathrm{DEG}}$ & 8.4 \\
\hline $\mathrm{LP}\left(\mathrm{O}_{\mathrm{OS}-1}\right)_{\mathrm{TFMS}}$ & $\sigma^{*}\left(\mathrm{OH}_{\mathrm{OH}-1}\right)_{\mathrm{DEG}}$ & 14.5 & $\sigma^{*}\left(\mathrm{OS}_{\mathrm{OS}-3}\right)_{\mathrm{TFMS} 2}$ & $\sigma^{*}\left(\mathrm{CH}_{\mathrm{CH}-1}\right)_{\mathrm{DEG}}$ & 7.8 \\
\hline $\mathrm{LP}\left(\mathrm{O}_{\mathrm{OS}-1}\right)_{\text {TFMS }}$ & $\sigma^{*}\left(\mathrm{OH}_{\mathrm{OH}-2}\right)_{\mathrm{DEG}}$ & 12.0 & & & \\
\hline $\mathrm{LP}\left(\mathrm{O}_{\mathrm{OS}-1}\right)_{\mathrm{TFMS}}$ & $\sigma^{*}\left(\mathrm{OH}_{\mathrm{OH}-1}\right)_{\mathrm{DEG}}$ & 10.0 & & & \\
\hline $\mathrm{LP}\left(\mathrm{O}_{\mathrm{OS}-1}\right)_{\text {TFMS }}$ & $\sigma^{*}\left(\mathrm{OH}_{\mathrm{OH}-2}\right)_{\mathrm{DEG}}$ & 11.6 & & & \\
\hline
\end{tabular}




\begin{tabular}{|c|c|c|c|c|c|}
\hline $\mathrm{LP}\left(\mathrm{O}_{\mathrm{OH}-1}\right)_{\mathrm{DEG}}$ & $\sigma^{*}\left(\mathrm{CH}_{\text {cyc }-0}\right)_{\text {BMI-1 }}$ & 5.6 & $\mathrm{LP}\left(\mathrm{O}_{\mathrm{OH}-1}\right)_{\mathrm{DEG}}$ & $\sigma^{*}\left(\mathrm{CH}_{\text {methyl }}\right)_{\mathrm{BMI}}$ & 5.5 \\
\hline $\mathrm{LP}\left(\mathrm{O}_{\mathrm{OH}-1}\right)_{\mathrm{DEG}}$ & $\sigma^{*}\left(\mathrm{CH}_{\mathrm{cyc}-0}\right)_{\mathrm{BMI}-1}$ & 31.3 & $\mathrm{LP}\left(\mathrm{F}_{\mathrm{BF}-3}\right)_{\mathrm{BF} 4-1}$ & $\sigma^{*}\left(\mathrm{OH}_{\mathrm{OH}-2}\right)_{\mathrm{DEG}}$ & 8.0 \\
\hline $\mathrm{LP}\left(\mathrm{O}_{\mathrm{OH}-2}\right)_{\mathrm{DEG}}$ & $\sigma^{*}\left(\mathrm{CH}_{\mathrm{cyc}-0}\right)_{\mathrm{BMI}-2}$ & 9.8 & $\mathrm{LP}\left(\mathrm{F}_{\mathrm{BF}-3}\right)_{\mathrm{BF} 4-1}$ & $\sigma^{*}\left(\mathrm{OH}_{\mathrm{OH}-2}\right)_{\mathrm{DEG}}$ & 46.6 \\
\hline $\mathrm{LP}\left(\mathrm{O}_{\mathrm{OH}-2}\right)_{\mathrm{DEG}}$ & $\sigma^{*}\left(\mathrm{CH}_{\text {butyl-1 }}\right)_{\text {BMI-1 }}$ & 7.7 & & & \\
\hline $\mathrm{LP}\left(\mathrm{O}_{\mathrm{OH}-2}\right)_{\mathrm{DEG}}$ & $\sigma^{*}\left(\mathrm{CH}_{\mathrm{cyc}-0}\right)_{\mathrm{BMI}-2}$ & 15.1 & & & \\
\hline $\mathrm{LP}\left(\mathrm{F}_{\mathrm{BF}-3}\right)_{\mathrm{BF} 4}$ & $\sigma^{*}\left(\mathrm{OH}_{\mathrm{OH}-1}\right)_{\mathrm{DEG}}$ & 9.3 & & & \\
\hline $\mathrm{LP}\left(\mathrm{F}_{\mathrm{BF}-3}\right)_{\mathrm{BF} 4}$ & $\sigma^{*}\left(\mathrm{OH}_{\mathrm{OH}-2}\right)_{\mathrm{DEG}}$ & 6.3 & & & \\
\hline $\mathrm{LP}\left(\mathrm{F}_{\mathrm{BF}-3}\right)_{\mathrm{BF} 4}$ & $\sigma^{*}\left(\mathrm{OH}_{\mathrm{OH}-1}\right)_{\mathrm{DEG}}$ & 13.5 & & & \\
\hline $\mathrm{LP}\left(\mathrm{F}_{\mathrm{BF}-3}\right)_{\mathrm{BF} 4}$ & $\sigma^{*}\left(\mathrm{OH}_{\mathrm{OH}-2}\right)_{\mathrm{DEG}}$ & 9.3 & & & \\
\hline $\mathrm{LP}\left(\mathrm{F}_{\mathrm{BF}-3}\right)_{\mathrm{BF} 4}$ & $\sigma^{*}\left(\mathrm{OH}_{\mathrm{OH}-1}\right)_{\mathrm{DEG}}$ & 11.6 & & & \\
\hline $\mathrm{LP}\left(\mathrm{F}_{\mathrm{BF}-3}\right)_{\mathrm{BF} 4}$ & $\sigma^{*}\left(\mathrm{OH}_{\mathrm{OH}-2}\right)_{\mathrm{DEG}}$ & 17.4 & & & \\
\hline \multicolumn{3}{|c|}{ (EMIFAP)EMI ${ }^{+}-1$} & \multicolumn{3}{|c|}{ (EMIFAP)FAP'-1 } \\
\hline $\mathrm{LP}\left(\mathrm{O}_{\mathrm{O}}\right)_{\mathrm{DEG}}$ & $\sigma^{*}\left(\mathrm{CH}_{\text {cyc-0}}\right)_{\text {EMI-1 }}$ & 5.8 & $\mathrm{LP}\left(\mathrm{O}_{\mathrm{O}}\right)_{\mathrm{DEG}}$ & $\sigma^{*}\left(\mathrm{CH}_{\mathrm{cyc}-0}\right)_{\mathrm{EMI}}$ & 9.4 \\
\hline $\mathrm{LP}\left(\mathrm{O}_{\mathrm{OH}-2}\right)_{\mathrm{DEG}}$ & $\sigma^{*}\left(\mathrm{CH}_{\mathrm{cyc}-0}\right)_{\mathrm{EMI}-1}$ & 17.4 & $\mathrm{LP}\left(\mathrm{O}_{\mathrm{O}}\right)_{\mathrm{DEG}}$ & $\sigma^{*}\left(\mathrm{CH}_{\mathrm{cyc}-0}\right)_{\mathrm{EMI}}$ & 6.7 \\
\hline $\mathrm{LP}\left(\mathrm{F}_{\mathrm{PF}-1}\right)_{\mathrm{FAP}}$ & $\sigma^{*}\left(\mathrm{OH}_{\mathrm{OH}-2}\right)_{\mathrm{DEG}}$ & 8.9 & & & \\
\hline
\end{tabular}

After initial DEG adsorption, we studied the growth of the DEG clusters on the CILSs by focusing on the most stable negatively and positively charged IL seeds. Note that these are not always the seeds leading to the best CILS-DEG adsorption $\Delta G$. However, since the "best" conformational composition with respect to DEG adsorption is likely to be different for each number of DEG, we selected the most stable "DEG-free" seeds to keep the comparison consistent. The obtained $\Delta G$ values for adsorption of 1-3 DEG molecules are given in Table S1 and the CILS-DEG structures are shown in Figure 4. The charge preference trend seen in Table 3 continues with the addition of further DEG molecules, corroborating our hypothesis that single-molecule adsorption studies are representative for the whole process. For both the positively and negatively charged EMITFMS and BMIBF4 seeds, nucleation starts by binding of a single DEG molecule to the TFMS and BF4 anions, but subsequent DEG molecules are then bound to the cations. For EMIFAP, the first and subsequent DEG molecules are all bound to the cations. For all CILSs, the intramolecular hydrogen bonding between the DEG 
molecules further promotes the heterogeneous nucleation process, with the addition of the second DEG molecule often (in 5 of 6 cases) being even more favorable than the first (see Table S1).

CILS

O DEG

$\sum_{i=1}^{+\infty}$

$\sum_{i=1}^{\infty}$

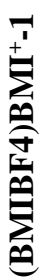

章
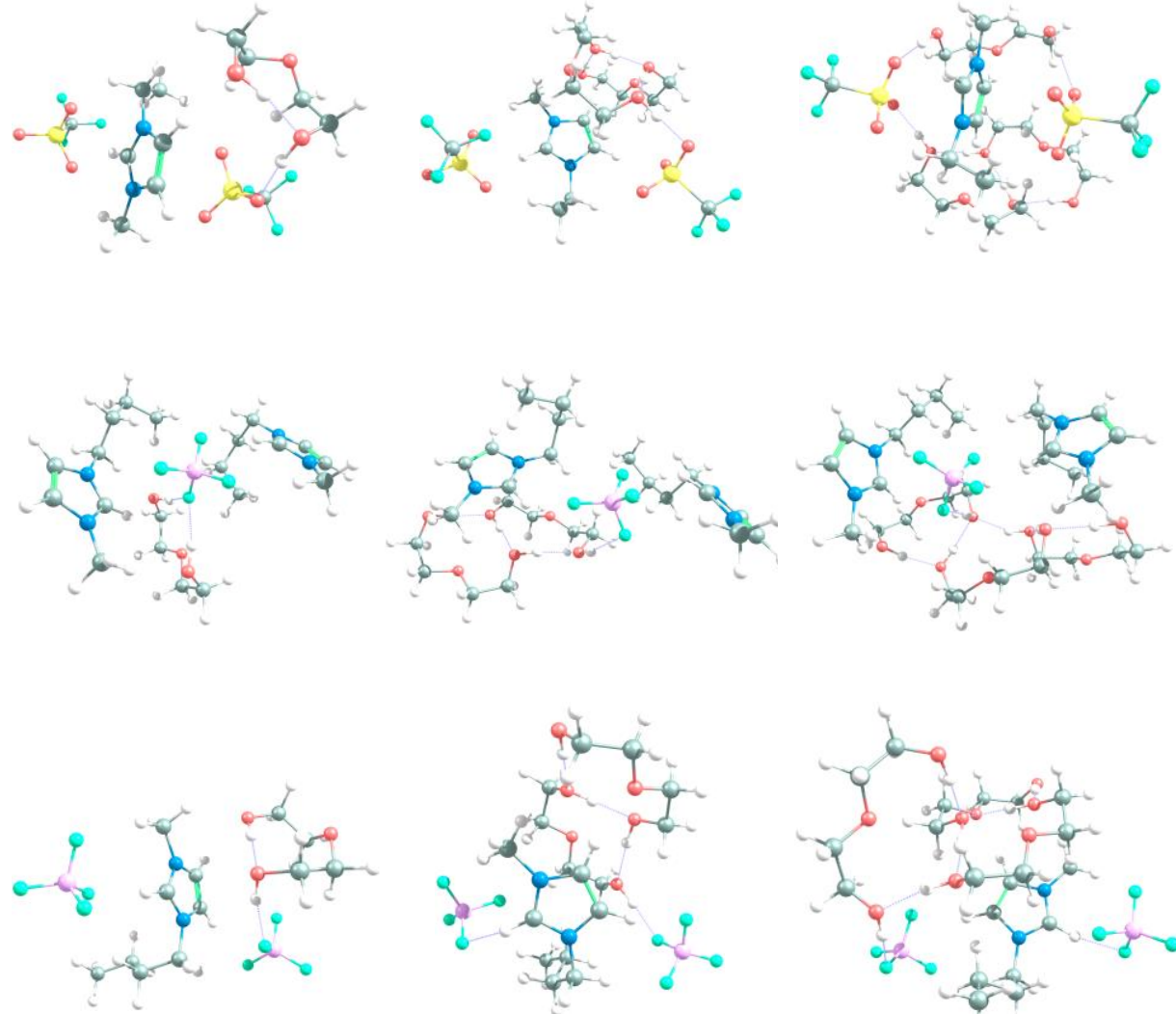

3 DEG
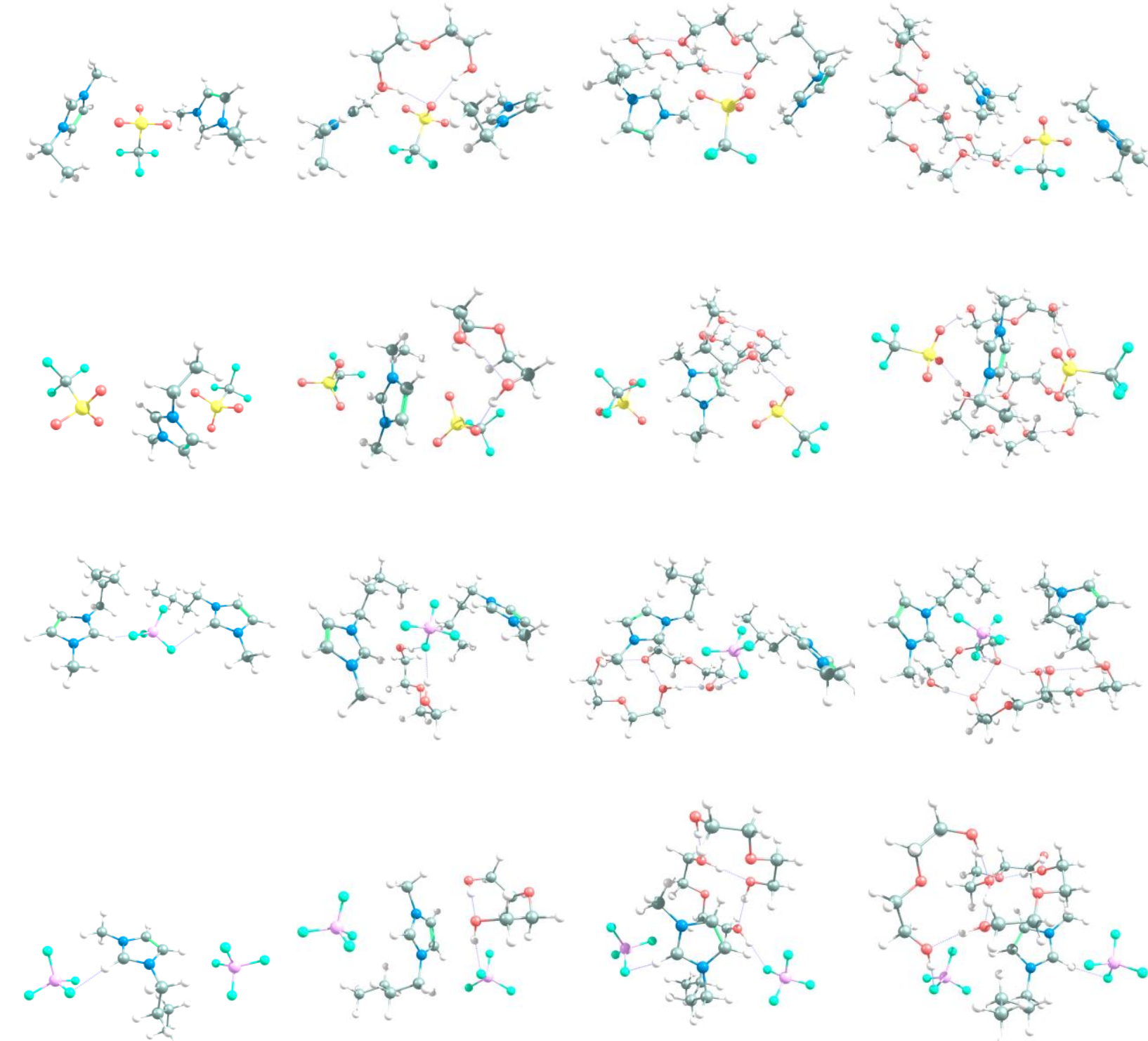
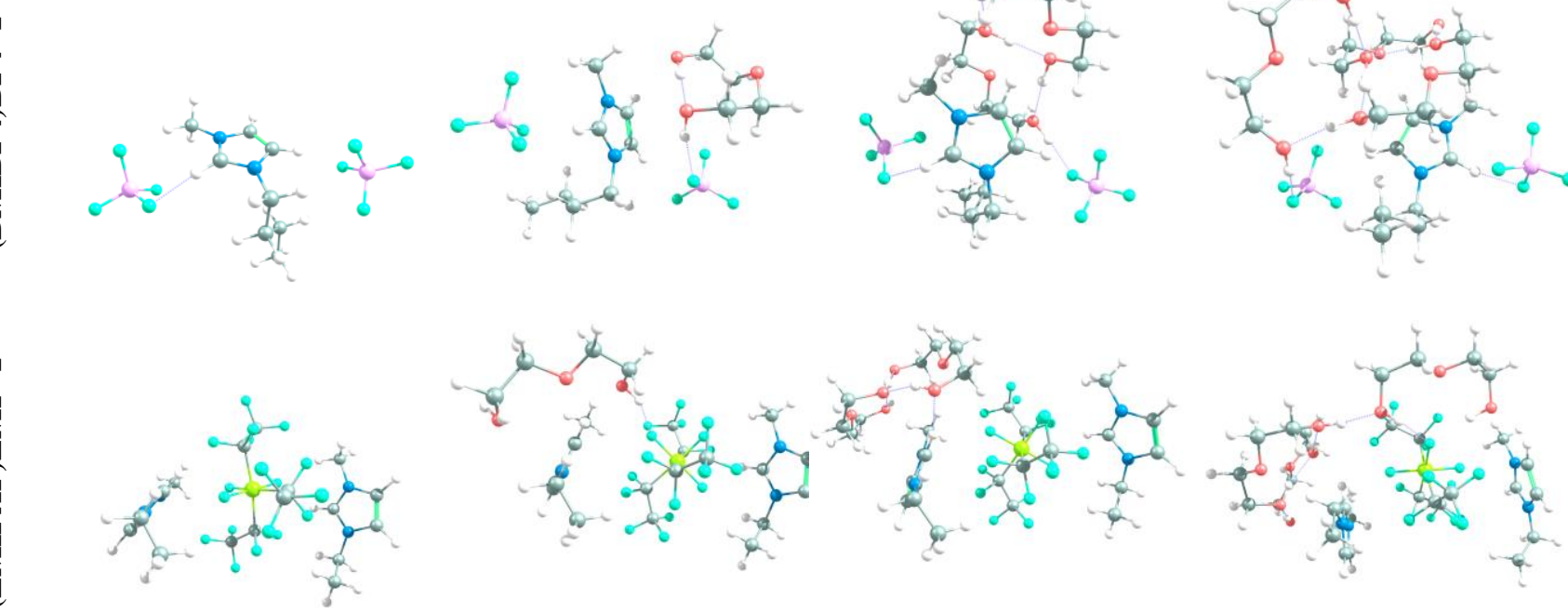

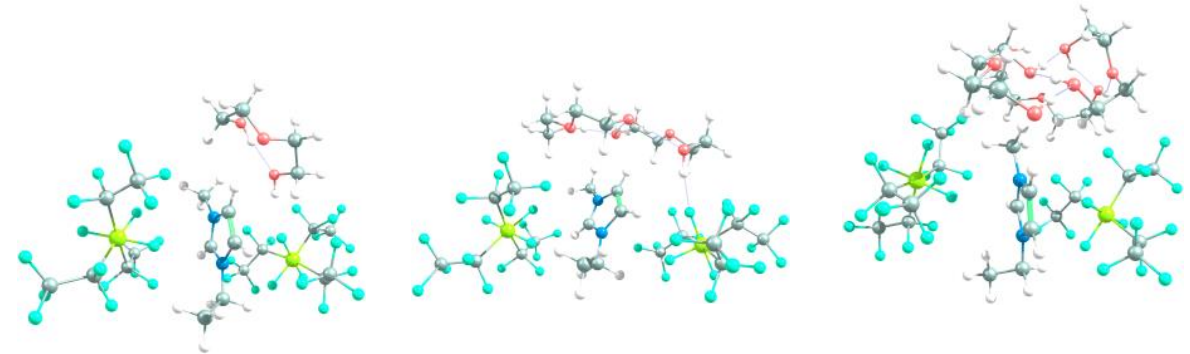

Figure 4. The starting steps of DEG nucleation on the CILSs at $298.15 \mathrm{~K}$ and the $6 \mathrm{~b} 97 \mathrm{X}-\mathrm{D} / 6-$ $31+\mathrm{G}^{*}$ level of theory. The viewing angles are chosen to best clarify the interaction networks. The blue dotted lines represent the hydrogen bonds.

\section{CONCLUSION}

In general, both experimental and theoretical results indicate that DEG nucleation on the CILSs displays a positive sign preference. The quantum chemical calculations are able to generate CILS models with CCSs very close to that of the experimentally produced seeds. Also, modeling single molecules adsorbing to the smallest possible charged seeds can capture the sign preference and the overall differences in the nucleating abilities of the different ionic liquids. This suggests that such relatively simple model calculations can be immensely useful in predicting and explaining nucleation of complex seed-vapor mixtures. The experimentally observed differences between the CILSs are caused by the hydrogen bonding patterns. For example, positive seeds tend to form both stronger and more numerous hydrogen bonds with DEG. This leads to lower adsorption free energies, and consequently lower onset supersaturations for heterogeneous nucleation onto the cationic seeds. 


\section{SUPPORTING INFORMATION}

Details of the experimental and computational methods, structures of the ionic liquids, diethylene glycol, the selected anion/cation conformers/configurations and the CILSs, effect of conformational/configurational diversity on the CILSs, NBO results of the 1 DEG-CILS systems, adsorption energies for the addition of two and three DEG molecules to the CILSs, and the geometry and frequencies (output files) of all seeds and DEG-CILS complexes.

\section{ACKNOWLEDGEMENTS}

The experimental work was conducted at Yale University and we are grateful to Prof. Juan Fernandez de la Mora for the access to the laboratory facilities and his help in operating the cluster production setup. We thank Prof. Carlos Larriba and Ivo Neefjes for helpful discussions related to CCS modeling. This work was financially supported by UHEL Faculty of Science support grant (75284140) and ATMATH Project and UHEL 3-year grant (75284132), European Research Council project 692891DAMOCLES, and Academy of Finland (1325656). The computational resources supplied by the CSC-IT Center for Science in Espoo, Finland, are greatly acknowledged.

\section{REFERENCES}

(1) Murty, B. S.; Kori, S. A.; Chakraborty, M. Grain Refinement of Aluminium and Its Alloys by Heterogeneous Nucleation and Alloying. Int. Mater. Rev. 2002, 47, 3-29.

(2) Zhai, W. T.; Yu, J.; Wu, L. C.; Ma, W. M.; He, J. S. Heterogeneous Nucleation Uniformizing Cell Size Distribution in Microcellular Nanocomposites Foams. Polymer 2006, 47, 7580-7589. 
(3) Zhao, J. J.; Wang, M. H.; Jebutu, M. S.; Zhu, M. H.; Gleason, K. K. Fundamental Nanoscale Surface Strategies for Robustly Controlling Heterogeneous Nucleation of Calcium Carbonate. $J$. Mater. Chem. A 2019, 7, 17242-17247.

(4) Meng, Q.; Deng, B.; Zhang, H.; Wang, B.; Zhang, W.; Wen, Y.; Ming, H.; Zhu, X.; Guan, Y.; Xiang, Y.; et al. Heterogeneous Nucleation and Growth of Electrodeposited Lithium Metal on the Basal Plane of Single-Layer Graphene. Energy Storage Mater. 2019, 16, 419-425.

(5) Murray, B. J.; Wilson, T. W.; Dobbie, S.; Cui, Z.; Al-Jumur, S. M.; Möhler, O.; Schnaiter, M.; Wagner, R.; Benz, S.; Niemand, M.; et al. Heterogeneous Nucleation of Ice Particles on Glassy Aerosols under Cirrus Conditions. Nat. Geosci. 2010, 3, 233-237.

(6) Zuberi, B.; Bertram, A. K.; Cassa, C. A.; Molina, L. T.; Molina, M. J. Heterogeneous Nucleation of Ice in $\left(\mathrm{NH}_{4}\right)(2) \mathrm{SO}_{4}{ }^{-} \mathrm{H}_{2} \mathrm{O}$ Particles with Mineral Dust Immersions. Geophys. Res. Lett. $2002,29$.

(7) Jun, Y. S.; Kim, D.; Neil, C. W. Heterogeneous Nucleation and Growth of Nanoparticles at Environmental Interfaces. Accounts Chem. Res. 2016, 49, 1681-1690.

(8) Park, Y.; Wyslouzil, B. E. $\mathrm{CO}_{2}$ Condensation onto Alkanes: Unconventional Cases of Heterogeneous Nucleation. Phys. Chem. Chem. Phys. 2019, 21, 8295-8313.

(9) Page, A. J.; Sear, R. P. Heterogeneous Nucleation in and out of Pores. Phys. Rev. Lett. 2006, 97, 065701-065704.

(10) Varanasi, K. K.; Hsu, M.; Bhate, N.; Yang, W. S.; Deng, T. Spatial Control in the Heterogeneous Nucleation of Water. Appl. Phys. Lett. 2009, 95, 094101-094103.

(11) Winkler, P. M.; Steiner, G.; Vrtala, A.; Vehkamaki, H.; Noppel, M.; Lehtinen, K. E. J.; Reischl, G. P.; Wagner, P. E.; Kulmala, M. Heterogeneous Nucleation Experiments Bridging the Scale from Molecular Ion Clusters to Nanoparticles. Science 2008, 319, 1374-1377.

(12) Kangasluoma, J.; Samodurov, A.; Attoui, M.; Franchin, A.; Junninen, H.; Korhonen, F.; Kurtén, T.; Vehkamäki, H.; Sipilä, M.; Lehtipalo, K.; et al. Heterogeneous Nucleation onto Ions and Neutralized Ions: Insights into Sign-Preference. J. Phys. Chem. C 2016, 120, 7444-7450. 
(13) Winkler, P. M.; Hienola, A.; Steiner, G.; Hill, G.; Vrtala, A.; Reischl, G. P.; Kulmala, M.; Wagner, P. E. Effects of Seed Particle Size and Composition on Heterogeneous Nucleation of NNonane. Atmos. Res. 2008, 90, 187-194.

(14) Tauber, C.; Chen, X. S.; Wagner, P. E.; Winkler, P. M.; Hogan, C. J.; Maisser, A. Heterogeneous Nucleation onto Monoatomic Ions: Support for the Kelvin-Thomson Theory. ChemPhysChem 2018, 19, 3144-3149.

(15) Winkler, P. M.; Steiner, G.; Vrtala, A.; Reischl, G. P.; Kulmala, M.; Wagner, P. E. Unary and Binary Heterogeneous Nucleation of Organic Vapors on Monodisperse Wox Seed Particles with Diameters Down to 1.4 Nm. Aerosol Sci. Tech. 2011, 45, 493-498.

(16) Iida, K.; Stolzenburg, M. R.; McMurry, P. H. Effect of Working Fluid on Sub-2 nm Particle Detection with a Laminar Flow Ultrafine Condensation Particle Counter. Aerosol Sci. Tech. 2009, 43, 81-96.

(17) Tauber, C.; Steiner, G.; Winkler, P. M. Counting Efficiency Determination from Quantitative Intercomparison between Expansion and Laminar Flow Type Condensation Particle Counter. Aerosol Sci. Tech. 2019, 53, 344-354.

(18) Kupc, A.; Winkler, P. M.; Vrtala, A.; Wagner, P. Unusual Temperature Dependence of Heterogeneous Nucleation of Water Vapor on Ag Particles. Aerosol Sci. Tech. 2013, 47, I-IV.

(19) Oberreit, D. R.; McMurry, P. H.; Hogan, C. J. Analysis of Heterogeneous Uptake by Nanoparticles Via Differential Mobility Analysis-Drift Tube Ion Mobility Spectrometry. Phys. Chem. Chem. Phys. 2014, 16, 6968-6979.

(20) Nasibulin, A. G.; de la Mora, J. F.; Kauppinent, E. I. Ion-Induced Nucleation of Dibutyl Phthalate Vapors on Spherical and Nonspherical Singly and Multiply Charged Polyethylene Glycol Ions. $J$. Phys. Chem. A 2008, 112, 1133-1138. 
(21) Schobesberger, S.; Winkler, P. M.; Pinterich, T.; Vrtala, A.; Kulmala, M.; Wagner, P. E. Experiments on the Temperature Dependence of Heterogeneous Nucleation on Nanometer-Sized Nacl and Ag Particles. ChemPhysChem 2010, 11, 3874-3882.

(22) Seto, T.; Okuyama, K.; de Juan, L.; Fernandéz de la Mora, J. Condensation of Supersaturated Vapors on Monovalent and Divalent Ions of Varying Size. J. Phys. Chem. 1997, 107, 1576-1585.

(23) Gamero-Castano, M.; Fernandéz de la Mora, J. Ion-Induced Nucleation: Measurement of the Effect of Embryo's Size and Charge State on the Critical Supersaturation. J. Chem. Phys. 2002, 117, 3345-3353.

(24) Fernandéz de la Mora, J. Heterogeneous Nucleation with Finite Activation Energy and Perfect Wetting: Capillary Theory Versus Experiments with Nanometer Particles, and Extrapolations on the Smallest Detectable Nucleus. Aerosol Sci. Tech. 2011, 45, 543-554.

(25) Wilson, C. T. R. On the Condensation Nuclei Produced in Gases by the Action of Röntgen Rays, Uranium Rays, Ultra-Violet Light, and Other Agents. Philos. Trans. Royal Soc. London 1899, 192, 403-453.

(26) Kane, D.; Daly, G. M.; El-Shall, S. Condensation of Supersaturated Vapors on Benzene Ions Generated by Resonant Two-Photon Ionization: A New Technique for Ion Nucleation. J. Phys. Chem. 1995, 99, 7867-7870.

(27) Adachi, M.; Okuyama, K.; Seinfeld, J. H. Experimental Studies on Ion-Induced Nucleation. J. Aerosol Sci. 1992, 23, 327-337.

(28) Katz, J. L.; Fisk, J. A.; Chakarov, V. M. Condensation of a Supersaturated Vapor Ix. Nucleation on Ions. J. Chem. Phys. 1994, 101, 2309-2318.

(29) Rabeony, H.; Mirabel, P. Experimental Study of Vapor Nucleation on Ions. J. Phys. Chem. 1987, 91, 1815-1818. 
(30) Abdelsayed, V.; El-Shall, M. S. Vapor Phase Nucleation on Neutral and Charged Nanoparticles: Condensation of Supersaturated Trifluoroethanol on Mg Nanoparticles. J. Chem. Phys. 2007, 126, 024706-024711.

(31) Abdelsayed, V.; El-Shall, M. S. Direct Observation of Metal Nanoparticles as Heterogeneous Nuclei for the Condensation of Supersaturated Organic Vapors: Nucleation of Size-Selected Aluminum Nanoparticles in Acetonitrile and N-Hexane Vapors. J. Chem. Phys. 2014, 141, 054710054717.

(32) Sipilä, M.; Lehtipalo, K.; Attoui, M.; Neitola, K.; Petaja, T.; Aalto, P. P.; O'Dowd, C. D.; Kulmala, M. Laboratory Verification of Ph-Cpc's Ability to Monitor Atmospheric Sub-3 nm Clusters. Aerosol Sci. Tech. 2009, 43, 126-135.

(33) Kuang, C. A.; Chen, M. D.; McMurry, P. H.; Wang, J. Modification of Laminar Flow Ultrafine Condensation Particle Counters for the Enhanced Detection of $1 \mathrm{Nm}$ Condensation Nuclei. Aerosol Sci. Tech. 2012, 46, 309-315.

(34) Gamero-Castano, M.; Fernandéz de la Mora, J. A Condensation Nucleus Counter (CNC) Sensitive to Singly Charged Sub-Nanometer Particles. J. Aerosol Sci. 2000, 31, 757-772.

(35) Kangasluoma, J.; Kuang, C.; Wimmer, D.; Rissanen, M. P.; Lehtipalo, K.; Ehn, M.; Worsnop, D. R.; Wang, J.; Kulmala, M.; Petaja, T. Sub-3 nm Particle Size and Composition Dependent Response of a Nano-Cpc Battery. Atmos. Meas. Tech. 2014, 7, 689-700.

(36) Kangasluoma, J.; Junninen, H.; Lehtipalo, K.; Mikkila, J.; Vanhanen, J.; Attoui, M.; Sipila, M.; Worsnop, D.; Kulmala, M.; Petaja, T. Remarks on Ion Generation for CPC Detection Efficiency Studies in Sub-3-nm Size Range. Aerosol Sci. Tech. 2013, 47, 556-563.

(37) Kathmann, S. M.; Schenter, G. K.; Garrett, B. C. Ion-Induced Nucleation: The Importance of Chemistry. Phys. Rev. Lett. 2005, 94, 116104.

(38) Oh, K. J.; Gao, G. T.; Zeng, X. C. Nucleation of Water and Methanol Droplets on Cations and Anions: The Sign Preference. Phys. Rev. Lett. 2001, 86, 5080-5083. 
(39) Nadykto, A. B.; Yu, F. Q.; Herb, J. Towards Understanding the Sign Preference in Binary Atmospheric Nucleation. Phys. Chem. Chem. Phys. 2008, 10, 7073-7078.

(40) Kurten, T.; Ortega, I. K.; Vehkamaki, H. The Sign Preference in Sulfuric Acid Nucleation. $J$. Mol. Struc. Theochem. 2009, 901, 169-173.

(41) Kangasluoma, J.; Hering, S.; Picard, D.; Lewis, G.; Enroth, J.; Korhonen, F.; Kulmala, M.; Sellegri, K.; Attoui, M.; Petaja, T. Characterization of Three New Condensation Particle Counters for Sub-3 nm Particle Detection During the Helsinki CPC Workshop: The Adi Versatile Water CPC, Tsi 3777 Nano Enhancer and Boosted Tsi 3010. Atmos. Meas. Tech. 2017, 10, 2271-2281.

(42) Larriba, C.; Hogan, C. J.; Attoui, M.; Borrajo, R.; Garcia, J. F.; de la Mora, J. F. The MobilityVolume Relationship Below n.0 Nm Examined by Tandem Mobility-Mass Measurement. Aerosol Sci. Tech. 2011, 45, 453-467.

(43) Frisch, M. J.; Trucks, G. W.; Schlegel, H. B.; Scuseria, G. E.; Robb, M. A.; Cheeseman, J. R.; Scalmani, G.; Barone, V.; Petersson, G. A.; Nakatsuji, H.; et al. Gaussian 16 Rev. A.01, Wallingford, CT, 2016.

(44) Grimme, S. Supramolecular Binding Thermodynamics by Dispersion-Corrected Density Functional Theory. Chem. Eur. J. 2012, 18, 9955-9964.

(45) Chon, N. L.; Lee, S. H.; Lin, H. A Theoretical Study of Temperature Dependence of Cluster Formation from Sulfuric Acid and Ammonia. Chem. Phys. 2014, 433, 60-66.

(46) Funes-Ardoiz, I.; Paton, R. S. Goodvibes V2. 0.2. 2016.

(47) Kubecka, J.; Besel, V.; Kurten, T.; Myllys, N.; Vehkamaki, H. Configurational Sampling of Noncovalent (Atmospheric) Molecular Clusters: Sulfuric Acid and Guanidine. J. Phys. Chem. A 2019, 123, 6022-6033.

(48) Coots, J.; Gandhi, V.; Onakoya, T.; Chen, X.; Larriba-Andaluz, C. A Parallelized Tool to Calculate the Electrical Mobility of Charged Aerosol Nanoparticles and Ions in the Gas Phase. J. Aerosol Sci. 2020, 147, 105570-105576. 
(49) Larriba, C.; Hogan, C. J. Momentum Transfer Collision Cross Sections and Ion Mobilities in Diatomic Gases: Measurement Vs. Prediction with Non-Specular Scattering Models. J. Phys. Chem. A 2013, 117, 3887-3901.

(50) Shrivastav, V. R. Optimization of Lennard-Jones Potential Parameters and Benchmark Comparison between Ion Mobility Calculators in Free Molecular Regime. PhD Thesis 2017, Purdue University.

(51) Maisser, A.; Hogan, C. J. Examination of Organic Vapor Adsorption onto Alkali Metal and Halide Atomic Ions by Using Ion Mobility Mass Spectrometry. ChemPhyschem 2017, 18, 3039-3046. 

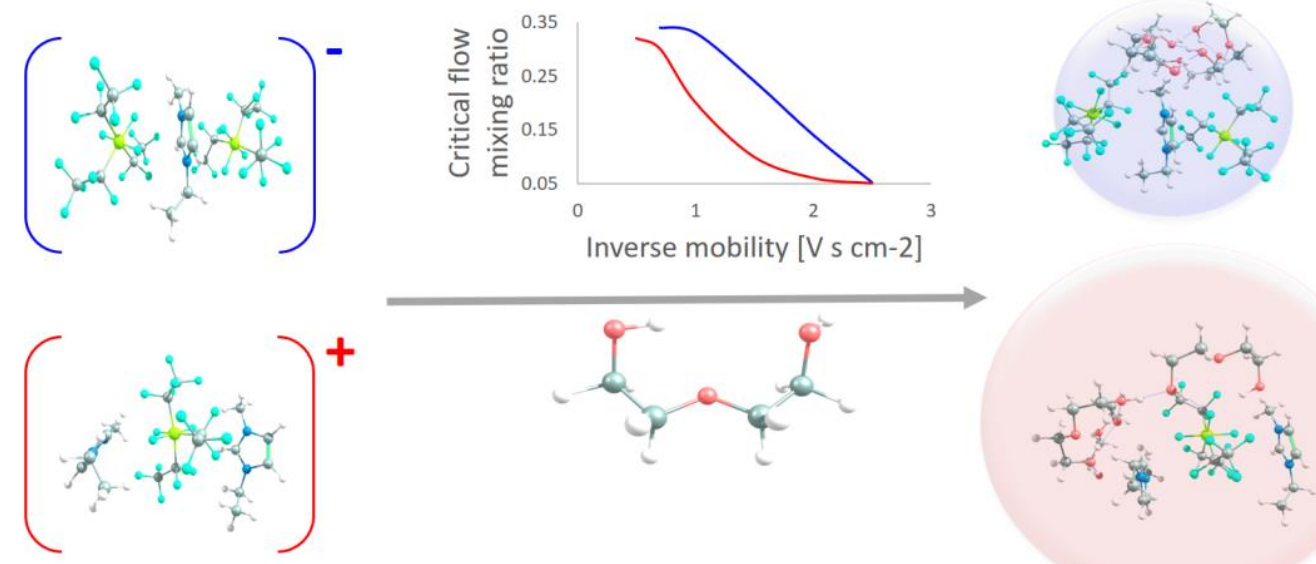